\title{
A High Throughput Targeted Gene Disruption Method for Alternaria brassicicola Functional Genomics Using Linear Minimal Element (LME) Constructs
}

\author{
Yangrae Cho, ${ }^{1}$ Joshua W. Davis, ${ }^{1}$ Kwang-Hyung Kim, ${ }^{1}$ Juan Wang, ${ }^{2}$ Qi-Hong Sun, ${ }^{1}$ \\ Robert A. Cramer, Jr., ${ }^{3}$ and Christopher B. Lawrence ${ }^{1}$ \\ ${ }^{1}$ Virginia Bioinformatics Institute, Blacksburg, VA 24061, U.S.A.; ${ }^{2}$ Department of Bioagricultural Sciences and Pest \\ Management, Colorado State University, Fort Collins, CO 80523, U.S.A.; ${ }^{3}$ Department of Molecular Genetics and \\ Microbiology, Duke University Medical Center, Duke University, Durham, NC 27708-9902, U.S.A.
}

Submitted 20 September 2005. Accepted 6 October 2005.

\begin{abstract}
Alternaria brassicicola causes black spot disease of cultivated Brassicas and has been used consistently as a necrotrophic fungal pathogen for studies with Arabidopsis. In A. brassicicola, mutant generation has been the most ratelimiting step for the functional analysis of individual genes due to low efficiency of both transformation and targeted integration. To improve the targeted gene disruption efficiency as well as to expedite gene disruption construct production, we used a short linear construct with minimal elements, an antibiotic resistance selectable marker gene, and a 250- to 600-bp-long partial target gene. The linear minimal element (LME) constructs consistently produced stable transformants for diverse categories of genes. Typically, $100 \%$ of the transformants were targeted gene disruption mutants when using the LME constructs, compared with inconsistent transformation and usually less than $10 \%$ targeted gene disruption with circular plasmid disruption constructs. Each mutant displayed a unique molecular signature thought to originate from endogenous exonuclease activities in fungal cells. Our data suggests that a DNA double-stranded break repair mechanism (DSBR) functions to increase targeting efficiency. This method is advantageous for high throughput gene disruption, overexpression, and reporter gene introduction within target genes, especially for asexual filamentous fungi where genetic approaches are unfavorable.
\end{abstract}

Complete genome sequences have been determined for over 100 model organisms, including the fungi Neurospora crassa, Aspergillus nidulans, and Candida albicans, to name a few (Galagan et al. 2003; Hynes 2003; Jones et al. 2004). In addition, several plant-pathogenic fungal genome sequencing projects have been completed recently, including Magnaporthe grisea, Stagonospora nodorum, Sclerotinia sclerotiorum, and Fusarium graminearum. The completion of genome sequencing projects has led research communities to develop approaches and methodologies to explore gene function on a genome-wide scale. Characterization of gene expression patterns and transcriptional regulatory networks are common applications of functional genomics. In addition, disruption of several thousand

Corresponding author: C. B. Lawrence; E-mail: lawrence@vbi.vt.edu; Telephone: +1.540 .231 .1907 . genes is desirable as a part of functional analysis of individual genes or when identifying genes that contribute to a phenotype such as plant pathogenicity (Sweigard and Ebbole 2001).

The imperfect filamentous fungus Alternaria brassicicola (Schwein, Wiltshire) causes black spot disease on a broad range of cultivated and weedy members within the Brassicaceae. Notably, A. brassicicola has been used as a true necrotrophic fungus for studies with Arabidopsis. Having genome sequences and functional methodologies developed for both plant and pathogen is advantageous for the elucidation of events occurring at the host-pathogen interface that ultimately determine the outcome of the interaction.

Targeted gene disruption or gene replacement, such as recombinational insertion of circular disruption constructs, recombinational replacement (Yang et al. 2004), or transposon arrayed gene knockout (Adachi et al. 2002; Hamer et al. 2001; Lo et al. 2003), is highly desirable for targeted mutational analysis in conjunction with a genome or large expressed sequence tag (EST) sequencing project. With the impending completion of the A. brassicicola genome sequencing project in 2006, development of high-efficiency gene disruption technology for functional analysis is critical for the identification of virulence factors. This technology also will be useful for identifying the functions of other genes of interest involved in a variety of biological processes.

Generation of gene disruption mutants is the most rate-limiting step for the functional analysis of individual genes in most filamentous fungi. Targeted gene disruption involves two separate processes, transformation of foreign DNA molecules into fungal cells and their integration into the genome. Even after successful transformation, very inefficient integration of disruption constructs is quite common among plant-associated filamentous fungi. For example, less than $1 \%$ of transformants were targeted gene disruption mutants in Septoria lycopersici when attempting to disrupt a tomatinase gene and in Acremonium chrysogenum to disrupt a transcription factor (MartinHernandez et al. 2000; Schmitt et al. 2004). In contrast, Alternaria alternata has been shown to exhibit exceptionally high efficiency for transformation and targeted gene disruption by homologous recombination. Approximately 90 transformants were generated with $1 \mu \mathrm{g}$ of plasmid construct that contained 3-kb-long rDNA cassette sequences whose sequences repeat over 200 times in the genome (Tsuge et al. 1990). Meanwhile, targeted gene disruption efficiency approached $100 \%$ for a 
melanin biosynthesis gene using linearized disruption constructs containing as short as $600 \mathrm{bp}$ of target sequence (Shiotani and Tsuge 1995).

A. brassicicola, in contrast to studies with other Alternaria spp., previously has been reported to exhibit very low efficiency for both transformation and targeted gene disruption. Yao and Köller (1995) reported a rare case of gene disruption in A. brassicicola for a cutinase gene cutab1. In this study, high-velocity microprojectiles (delivered via gene gun) were used to introduce circular plasmid constructs harboring a partial cutabl cDNA into conidia. Two targeted gene mutants were identified out of 30 hygromycin B (hygB) resistant transformants, whereas a polyethylene glycol (PEG)-mediated protoplast transformation method failed to generate any transformants. In the present study, we adopted a relatively easy and economical PEG-mediated protoplast transformation method to disrupt the function of individual genes by targeted gene disruption with an unconventional linear construct composed of an antibiotic resistance selectable marker gene at one side and a partial target gene sequence at the other side. The utility of this approach for high-throughput gene disruption and overexpression of target genes in A. brassicicola is discussed.

\section{RESULTS}

\section{PEG-mediated transformation}

of $A$. brassicicola protoplasts with circular plasmids.

Prior to initiating transformation experiments, we performed a hygB sensitivity assay and found that hygB in potato dextrose agar (PDA) media at $15 \mu \mathrm{g} / \mathrm{ml}$ was sufficient to abolish growth of A. brassicicola using several isolates of the fungus. Initial transformation experiments (PEG-mediated transformation of protoplasts) were performed using one isolate (ATCC34622) with various circular fungal transformation vectors, including pCB1636, pCB1004, pCT74, and pAN7-1 (Lorang et al. 2001; Punt et al. 1987; Sweigard et al. 1997). In some experiments, vectors were linearized by cutting with an appropriate restricttion enzyme prior to transformation. Regardless of vector used, transformation efficiency using circular plasmids was extremely

Table 1. Transformation frequencies of Alternaria brassicicola using diverse plasmid vectors

\begin{tabular}{|c|c|c|c|c|}
\hline Plasmid $^{\mathrm{a}}$ & $\begin{array}{c}\text { No. of } \\
\text { experiments }\end{array}$ & $\begin{array}{c}\text { A. brassicicola } \\
\text { isolates }\end{array}$ & $\begin{array}{c}\text { Trans } / \mathbf{1 0}^{7} \\
\text { protoplasts }^{\mathrm{b}}\end{array}$ & $\begin{array}{c}\text { Mutants/ } \\
\text { trans }^{c}\end{array}$ \\
\hline \multicolumn{5}{|l|}{ pCB 1004} \\
\hline uncut & 2 & ATCC 34622 & 0,0 & $\ldots$ \\
\hline HindIII & 2 & ATCC 34622 & 0,0 & $\ldots$ \\
\hline \multicolumn{5}{|l|}{ pAN 7-1 } \\
\hline uncut & 3 & АTCC 34622 & $0,0,0$ & $\ldots$ \\
\hline HindIII & 3 & ATCC34622 & $0,2,4$ & $\ldots$ \\
\hline \multicolumn{5}{|l|}{ pCT74 } \\
\hline uncut & 2 & ATCC 34622 & 2,1 & $\ldots$ \\
\hline \multicolumn{5}{|l|}{ pCB1636 } \\
\hline uncut & 3 & ATCC 34622 & $0,3,0$ & $\ldots$ \\
\hline HindIII & 3 & ATCC34622 & $0,5,3$ & $\ldots$ \\
\hline EcoRI & 3 & ATCC 34622 & $6,7,7$ & \\
\hline pCB-MFS* & 1 & ATCC34622 & 8 & $5 / 8$ \\
\hline pCB-CPS* & 1 & ATCC34622 & 20 & $1 / 20$ \\
\hline pCB-CYH* & 1 & ATCC 34622 & 32 & $2 / 32$ \\
\hline pCB-Altb1* & 1 & АТCС 96866 & 20 & $0 / 20$ \\
\hline pCB-MAPK* & 6 & ATCC96866 & $17 * *$ & $4 / 17$ \\
\hline pCB-LIP1* & 1 & АТCС 96866 & 7 & ND \\
\hline pCB-LIP2* & 3 & АТCС 96866 & $20 * *$ & $1 / 3$ \\
\hline pCB-LIP3* & 2 & АТCС 96866 & $7 * *$ & $3 / 4$ \\
\hline
\end{tabular}

${ }^{\text {a }}$ Asterisk $(*)$ indicates pCB1636 with partial A. brassicicola gene sequence; ** indicates total numbers of transformants from multiple experiments.

${ }^{\mathrm{b}}$ Number of transformants $/ 10^{7}$ protoplasts.

${ }^{c}$ Number of knock-out mutants/transformants examined. ND indicates not determined. low, with typically less than three hygB-resistant transformants generated per microgram of plasmid when using between $10^{6}$ and $10^{7}$ protoplasts (Table 1). In general, linearization of these circular plasmids prior to transformation increased transformation efficiency only slightly.

Transformation efficiency was improved dramatically up to 10 -fold in several cases with circular constructs using the pCB1636 vector harboring partial A. brassicicola gene sequences. Another isolate (ATCC96866) showed moderately high transformation efficiency with similar type constructs. However, targeting efficiency typically was less than $10 \%$ in both strains; thus, this approach was not suitable for highthroughput functional analysis of genes (Table 1). To potentially increase transformation and gene disruption efficiency, we elected to use a shorter, linear, double-stranded polymerase chain reaction (PCR) product with minimal elements, including a hygB resistance gene cassette and the various target gene fragments in subsequent transformation attempts in lieu of using the entire circularized construct.

\section{Linear minimal element constructs: new logic for fungal gene disruption.}

There are several established methods to disrupt target genes using diverse constructs. A representative circular disruption construct contains an internal fragment of a target gene cloned together with a selectable marker gene in a plasmid vector (Fig. 1A). A classic linear construct, represented by the replacement construct, flanks an antibiotic resistance or other appropriate selectable marker genes with two fragments representing $5^{\prime}$ and $3^{\prime}$ regions of a target gene (Fig. 1B). Derivatives of replacement constructs have been widely used in diverse filamentous fungi to either replace short segments within a target gene with a selectable marker gene or disrupt a target gene (Bussink and Osmani 1999; Shah-Mahoney et al. 1997; Shiotani and Tsuge 1995; Voigt et al. 2005). We generated a linear construct with a partial target gene at only one end and an antibiotic resistance selectable marker gene at the other end (Fig. 1C), and designated this as a linear minimal element (LME) disruption construct to distinguish from other types of linear constructs. Insertion of classic linear constructs by a single homologous recombination was reported as an undesirable side effect in several cases due to the circularization of the linear constructs after transformation (Bussink and Osmani 1999; Shah-Mahoney et al. 1997; Yang et al. 2004). In contrast, if the LME construct were circularized efficiently in the cell, gene disruption might occur by a single homologous recombination (Fig. 1C).

\section{Transformation and targeted gene disruption efficiency using LME constructs.}

We created over 20 individual disruption constructs, using the pCB1636 vector harboring partial cDNA sequences corresponding to A. brassicicola genes identified in various cDNA libraries from our laboratory, to ultimately evaluate their role in pathogenicity (Table 2). We produced LME disruption constructs by PCR-based amplification of the gene-specific fragments and the hygB resistance gene cassette with M13 forward and M13 reverse primers using plasmid constructs as template DNA.

To establish a new gene disruption method, we transformed the LME constructs primarily into an A. brassicicola isolate (ATCC96866) and several other isolates. Importantly, the whole genome draft sequence currently is being determined for the ATCC 96866 isolate. We tested LME constructs to disrupt genes encoding putative toxic proteins, hydrolytic enzymes, a signaling pathway component, a transcription factor, and an essential protein (Table 2). Numbers of transformants generated 


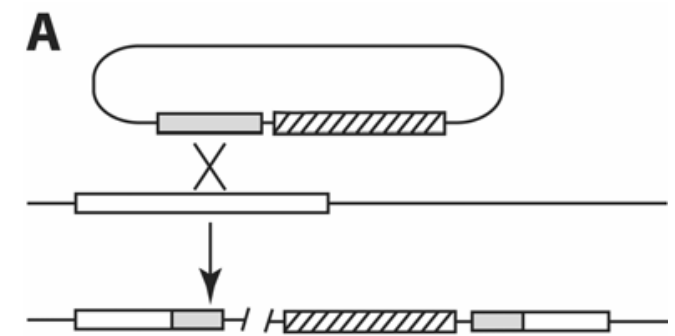

B
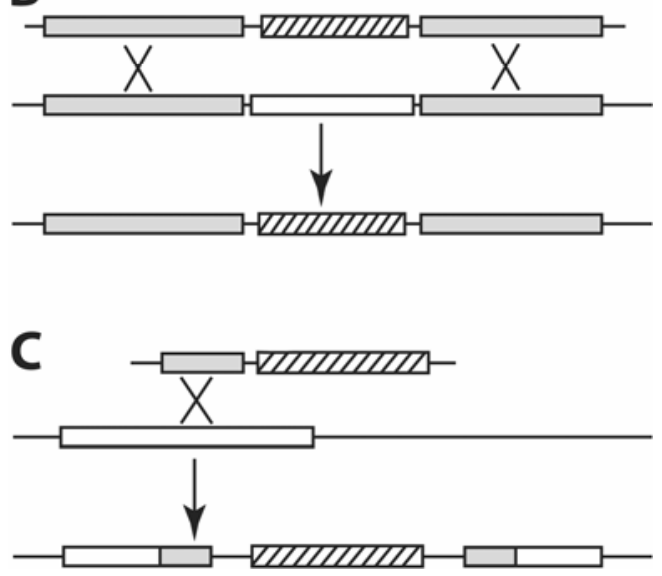

Fig. 1. Diagram depicting incorporation of transforming DNA at a target genomic locus. Shown are targeted gene disruption or replacement mechanisms starting with $\mathbf{A}$, a circular construct, $\mathbf{B}$, a linear recombinational gene replacement construct, and $\mathbf{C}$, a linear minimal element (LME) construct. Hatched box $=$ a selectable marker gene, white box $=$ a target genomic locus $(\mathrm{A}, \mathrm{B}$, and $\mathrm{C})$ and gray box = partial target gene $(\mathrm{A}$ and $\mathrm{C})$ or target flanking regions (B). Homologous recombination events are shown with a large "X" between target genomic locus and a partial target gene (A and C) or between target gene flanking regions (B). in these experiments ranged from 3 to 40 that emerged within 2 weeks on the selection plate for each gene except an essential gene (Table 2). Additional transformants surfaced after 16 days. Late-emerging transformants were not counted in this study because previously emerged colonies grew too large and overlapped the late-emerging colonies. On average, 15 transformants emerged within 16 days when we transformed $10 \mu \mathrm{g}$ of LME disruption constructs in $4 \times 10^{6}$ protoplasts with an optimized protocol.

We obtained $100 \%$ gene disruption efficiency according to PCR and Southern hybridization experiments in most of these experiments (see next section). In addition, no evidence of ectopic insertion was observed in the vast majority of targeted gene disruption mutants. One or two rounds of single-spore isolation on PDA media containing hygB were sufficient to purify mutants and eliminate contamination with wild-type nuclei. After the protocol was optimized, we transformed two additional isolates (ATCC36422 and AB7) to find comparably high $(100 \%)$ targeted gene disruption efficiency for three genes (Table 2). In addition, we encountered extremely high transformation efficiency using the AB7 isolate and we currently are testing the reproducibility of this result.

We qualitatively assessed stability of gene disruption mutants after one round of single-spore isolation with isolate ATCC96866. Three different hygB-resistant mutants for genes predicted to encode an fus3 MAP kinase, chymotrypsin, and $N$ acetylglucosaminidase were cultured on PDA media lacking hygB for approximately 1 week, and hyphal tips were repeatedly transferred on to new PDA plates. The repeated subculturing on PDA media did not change hygB resistance of the disruption mutants during the repeated hyphal tip transfers, even after five times. After isolation of new conidia produced during late stages of plant infection, we also tested growth ability of mutant conidia on hygB-containing PDA media several times with over 10 different mutants. In every case, recovered spores remained highly resistant to hygB at the levels used in our

Table 2. Efficiency of transformation and gene knockout in Alternaria brassicicola using linear minimal element (LME) constructs

\begin{tabular}{|c|c|c|c|c|}
\hline Gene $^{\mathrm{a}}$ & Strain & $\begin{array}{l}\text { Number of transformants/ } \\
1 \times 10^{6-7} \text { protoplasts }\end{array}$ & $\begin{array}{c}\text { Knock-out percentile } \\
\text { (no. of mutants/no. examined })^{b}\end{array}$ & Verification method $^{c}$ \\
\hline Fus3 MAP Kinase & ATCC96866 & 20 & $100(20 / 20)$ & Morphology/PCR/Southern \\
\hline Fus3 MAP Kinase & AB7 & 5 & $100(5 / 5)$ & Morphology \\
\hline Fus3 MAP Kinase & ATCC34622 & 1 & $100(1 / 1)$ & Morphology \\
\hline Hog MAP Kinase & ATCC96866 & 13 & ND & $\ldots$ \\
\hline Chymotrypsin & ATCC96866 & 10 & $83(4 / 5)$ & PCR \\
\hline $\mathrm{N}$-acetylglucosaminidase & ATCC96866 & 12 & $100(6 / 6)$ & Southern, PCR \\
\hline $\mathrm{N}$-acetylglucosaminidase & AB7 & 120 & $100(5 / 5)$ & PCR \\
\hline $\mathrm{N}$-acetylglucosaminidase & ATCC34622 & 7 & ND & $\ldots$ \\
\hline Glycosyl hydrolase & ATCC96866 & 15 & ND & $\ldots$ \\
\hline Pectate lyase & ATCC96866 & 10 & ND & $\ldots$ \\
\hline Pectate lyase & AB7 & 64 & $100(5 / 5)$ & PCR \\
\hline Pectate lyase & ATCC 34622 & 9 & $100(5 / 5)$ & PCR \\
\hline Zinc finger & ATCC96866 & 31 & $100(8 / 8)$ & Southern, PCR \\
\hline Polyketide synthase & ATCC96866 & 3 & $100(3 / 3)$ & Southern, PCR \\
\hline Altb1 Allergen & ATCC96866 & 4 & $100(4 / 4)$ & Southern, PCR \\
\hline ATP/ADP transporter & ATCC96866 & $>200$ & $98(196 / 200)$ & Viability \\
\hline Lipase 1-1 & ATCC 96866 & $>10$ & $100(5 / 5)$ & PCR \\
\hline Lipase1 & ATCC 96866 & 8 & $100(8 / 8)$ & Southern \\
\hline Lipase2 & ATCC 96866 & 15 & $100(6 / 6)$ & Southern \\
\hline Lipase3 & ATCC96866 & 14 & $93(13 / 14)$ & Southern \\
\hline Cutinase (CL394) & ATCC96866 & $>10$ & $100(6 / 6)$ & PCR \\
\hline $\mathrm{N}$-ace over(1) & ATCC96866 & $>10$ & $\ldots$ & QRT-PCR \\
\hline $\mathrm{N}$-ace over(2) & ATCC96866 & 34 & $\ldots$ & $\ldots$ \\
\hline $\mathrm{N}$-ace over (3) & ATCC 11680 & 15 & $\ldots$ & QRT-PCR \\
\hline $\mathrm{N}$-ace GFP & ATCC96866 & $>10$ & $\ldots$ & PCR \\
\hline
\end{tabular}

${ }^{a} \mathrm{~N}$-ace over(1) = overexpression of $N$-acetylglucosaminidase in wild type, $\mathrm{N}$-ace $(2)=$ overexpression in Fus3 MAP kinase mutant, and N-ace(3) = overexpression in A. alternata wild type.

b ND = not determined, A. brassicicola isolates (ATCC96866, ATCC34622, and AB7).

${ }^{\mathrm{c}} \mathrm{PCR}=$ polymerase chain reaction; $\mathrm{QRT}=$ quantitative real time. 
studies. Thus, we strongly believe that this transformation method produces highly stable, hygB-resistant transformants.

Mode of targeted gene disruption using LME constructs.

Here, we describe molecular data with two genes predicted to encode chymotrypsin and $\mathrm{N}$-acetylglucosaminidase to support efficiency and mode of gene disruption. For the gene predicted to encode a chymotrypsin-like enzyme, we randomly examined 5 of 10 hygB-resistant transformants generated with an LME disruption construct harboring a partial gene sequence. Following one round of single-spore isolation, we found that four of them were targeted gene disruption mutants, whereas one maintained the target gene intact based on PCR examination (Fig 2A). Thus, the transforming DNA in this case was inserted ectopically. In three of four chymotrypsin gene disruption mutants, there were two incomplete gene sequences flanking the hygB resistance cassette. Template genomic DNA isolated from one of the four disruption mutants generated PCR products from only one primer pair (Fig 2A, lane 5), suggesting molecular differences from other mutants (examples shown below).

We examined nine randomly selected hygB-resistant transformants generated with an appropriately designed LME disruption construct and following single spore isolation for another gene
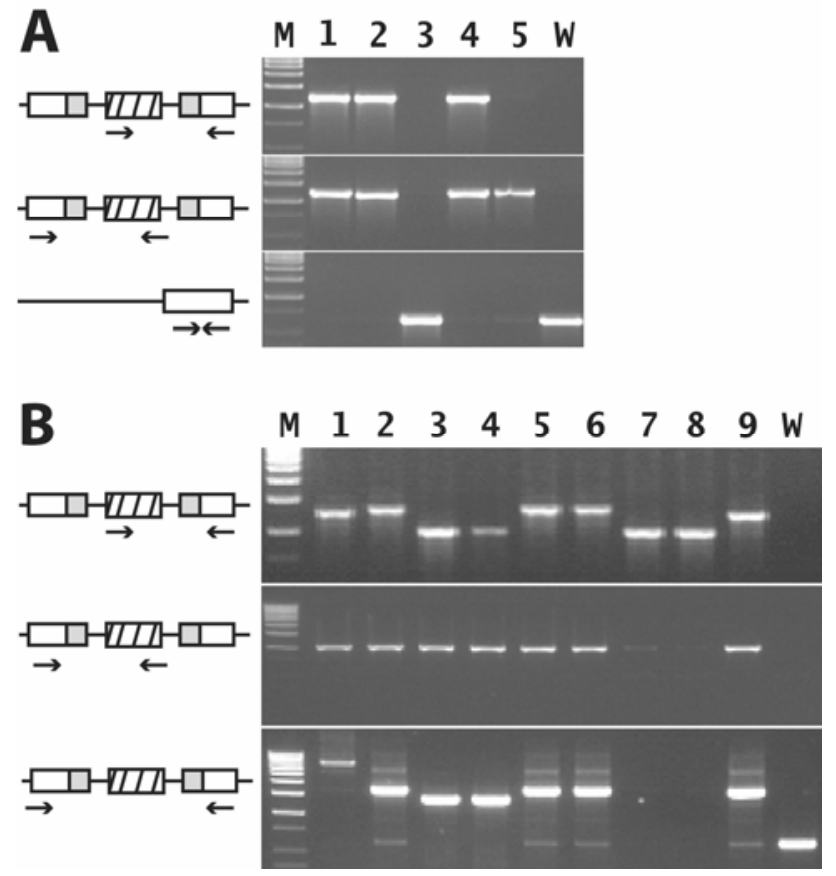

Fig. 2. Verification of targeted gene disruption by polymerase chain reaction (PCR) for $\mathbf{A}$, chymotrypsin gene and $\mathbf{B}, \mathrm{N}$-acetylglucosaminidase gene. PCR amplification was performed with two pairs of target genespecific and hygB resistance gene primers (top two panels) and a pair of solely gene-specific primers (bottom panel). Relative primer binding locations are marked below the schematic diagram of the disrupted target gene on the left side of gel images. The diagrams were drawn with a hypothesis that the target gene was disrupted via single homologous recombination with a circularized linear minimal element (LME) construct. Band sizes corresponding to three mutants (ace2, ace5, and ace6) were similar to the expected ones based on a single copy insertion of an LME construct. Notice variation in PCR product size corresponding to other mutants. Hatched box $=$ a selectable marker gene, white box $=$ a target genomic locus, and gray box = partial target gene. Weak bands on the third panel for the $N$-acetylglucosaminidase gene are due to minor contamination of wildtype nuclei or heterokaryons. These were undetected by Southern hybridizations even after an extreme exposure. Amplification was performed with Taq polymerase for PCR reactions shown in the first five panels (top to bottom) and with Accuprime Taq (Invitrogen, Carlsbad, CA, U.S.A.) for reactions depicted in the last panel due to long (over $3 \mathrm{~kb}$ ) expected product size. $M=1-\mathrm{kb}$ molecular marker (NEB, Beverly, MA, U.S.A.). predicted to encode $\mathrm{N}$-acetylglucosaminidase. Interestingly, disruption mutants generated with this construct showed at least four PCR amplification patterns (Fig 2B). Three of nine transformants (designated ace2, ace5, and ace6) produced PCR products (Fig 2B) and Southern hybridization patterns that would be expected from a mutant with a single-copy insertion of an LME construct in the target gene (Fig 3). The other six transformants also produced PCR products and Southern hybridization results expected from targeted gene disruption mutants in principle, but they presented unusual features. For example, PCR and Southern hybridization patterns generated from ace1 and ace7 genomic DNA indicated 3 and $>10$ copies of insertion of the LME constructs in the target gene, respectively. Interestingly, three transformants (ace3, ace4, and ace9) showed smaller amplifica-
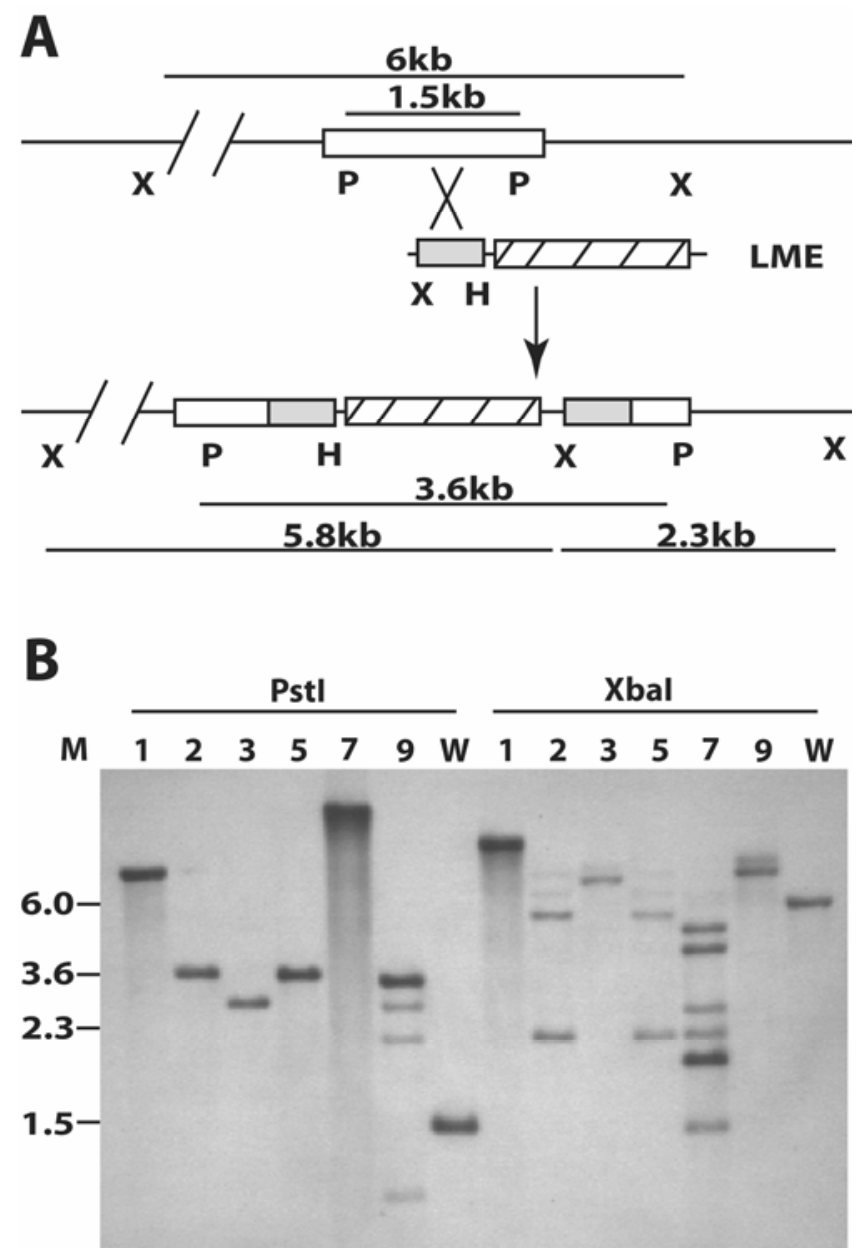

Fig. 3. Restriction map and Southern blot analysis of $N$-acetylglucosaminidase gene mutants. A, Restriction map of the $N$-acetylglucosaminidase genomic locus, the linear minimal element (LME) disruption construct, consisting of a 600-bp partial gene fragment (gray) and $1.5-\mathrm{kb}$ hygB resistance gene cassette (hatched box), and a typical gene disruption mutant locus. The expected disruption mutant genomic locus diagram is based on a single homologous recombination occurring between the target gene and a circularized LME construct. $\mathrm{P}=$ Pst $\mathrm{I}, \mathrm{X}=X b a \mathrm{I}$, and $\mathrm{H}=$ HindIII. B, Southern hybridization of genomic DNA from $N$-acetylglucosaminidase disruption mutants (1 through 9) and wild type (w). Each DNA set was digested with PstI or XbaI. The blot was probed with digoxigeninlabeled partial target sequence contained in the disruption construct (gray box). All disruption mutants showed variation in band size compared with the wild type. Two mutants (ace2 and ace5) showed the banding patterns and sizes expected based on the schematic diagram (A). Loss of XbaI site is apparent for ace 1 , ace 3 , and ace9. Origin of relatively faint bands corresponding to ace9 was not able to be determined. Estimated size of DNA fragments were marked on left and based on 1-kb ladder (Fisher Scientific, Atlanta, GA, U.S.A.). 
tion products in PCR experiments than the first three single-insertion mutants (ace2, ace5, and ace6) (Fig 2B). Southern blotting experiments revealed more complex hybridization patterns using genomic DNA isolated from ace3, ace4, and ace9 mutants compared with ace2, ace5, and ace6 (Fig 3B).

We next determined DNA sequences of PCR products at the target gene locus (Fig 2B) amplified from genomic DNA extracted from the individual mutants to verify arrangement and sequence length of the target gene and the LME construct. These PCR products were amplified using two pairs of gene specific primers; thus, hygB resistance-gene-specific primers would amplify the genomic locus harboring the LME construct. DNA sequencing of PCR products revealed typical arrangement of a genomic locus that has undergone a single homologous recombination with a circular disruption plasmid (Fig. 4). Noticeably, the M13F and M13R side vector sequences existed facing away from each other in mutants. Collectively, these observations strongly suggested that the target gene disruption occurred by homologous recombination with a circularized LME construct.

Consistent with the PCR and Southern hybridization results, length variation among mutants solely originated from deletions at the ends of LME constructs (Fig. 4). Sequence lengths in all mutants were shorter than the expected size, ranging from 38- to 667-bp deletions. Based on characterization of the 14 transformants, it is apparent that targeted gene disruption by homologous recombination is a predominant mechanism over ectopic insertion of the LME constructs. Finally, endogenous exonuclease digestion and circularization of LME constructs appears to precede the homologous recombination.

\section{Application of LME constructs: green fluorescent protein tagging of mutants and targeted gene overexpression mutants.}

The LME disruption constructs consistently produced targeted gene disruption mutants for various genes with close to $100 \%$ efficiency. We used the same method to tag the mutants with green fluorescent protein (GFP) gene simultaneously during the targeted gene disruption process. We added a 1,345-bplong GFP expression cassette in front of the $N$-acetylglucosaminidase disruption constructs (Fig. 5, diagram). Over 10 transformants were produced in approximately 11 days. Because we knew the targeted gene disruption efficiency was close to $100 \%$, we examined two of the early emerging transformants to find both targeted gene disruption mutants (data not shown). The GFP was expressed constitutively due to the ToxA promoter at the 5' side of the GFP coding gene (Lorang et al. 2001). The mutants were subjected to visualization with a fluorescence microscope. $\mathrm{N}$-acetylglucosaminidase mutants made the typical appressoria like structure during plant infection (Fig. 5, right), but not during saprophytic growth on a PDA plate (Fig. 5 , left).

Furthermore, we tested a novel possibility of using the LME construct approach to overexpress target genes. We made new LME constructs for the $N$-acetylglucosaminidase gene with a new antibiotic-resistant selectable marker gene (nourseothricin acetyltransferase) under control of the OliC promoter. In addition to this cassette, constructs contained two constitutive promoters (TrpC and ToxA) followed by the start codon of the $\mathrm{N}$ acetylglucosaminidase gene (Fig. 6, diagram). We transformed PCR products corresponding to the 3.8 -kb-long LME overex-
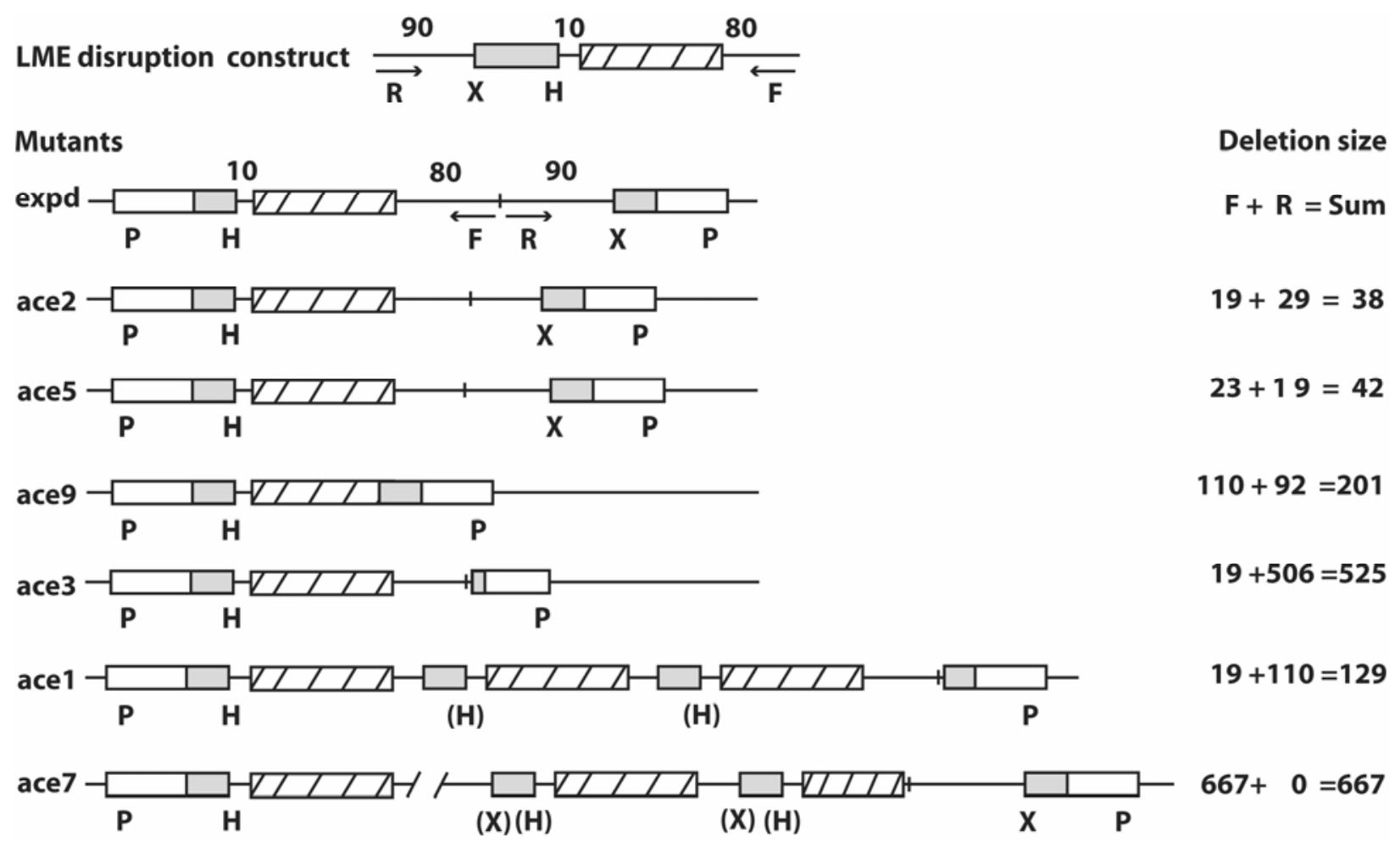

Fig. 4. Schematic diagram of targeted gene disruption with linear minimal element (LME) construct. Vector fragment at both ends of the initial construct is marked with F and R (M13 forward and reverse priming sites) with sequence directions (arrows). The length (bp) of vector sequence is shown at three locations (90, 10, and 80). The symbol (expd) represents targeted gene disruption by a single homologous recombination between a circularized LME construct and the target gene, whereas others show gene organization of actual mutants based on three lines of evidence: polymerase chain reaction (PCR) product size, Southern hybridization banding patterns, and sequence verification of PCR products for all except ace9. The ace9 diagram is based solely on PCR product size and sequence information. A short vertical line in the diagram of mutants is a boundary between both ends of vector fragment. The distance between the vertical line and adjacent boxes represents the length of nucleotides present. The extent (base pairs) of nucleotide deletion at M13F and M13R sides is depicted on far right. The symbol ( ) indicates probable presence of restriction enzyme site that was not experimentally tested. Abbreviations: $\mathrm{H}=\mathrm{HindIII}$, $\mathrm{X}=$ $X b a \mathrm{I}$, and $\mathrm{P}=$ Pst $\mathrm{I}$. 
pression construct generated with M13 forward and M13 reverse primers. We acquired 34 transformants from a single transformation experiment (Table 2). We examined RNA expression levels for the target gene with eight transformants in A. brassicicola wild-type background in the order of emergence from the transformation plates. According to the real-time quantitative reverse transcription PCR, three of six mutants expressed 10- to 20-fold more transcripts, whereas others produced approximately threefold or similar amounts of transcripts compared with the wild type (Fig. 6A). The same overexpression construct was used to transform A. alternata to produce 15 transformants. Three of eight examined transformants produced 25- to 30 -fold more transcripts than the A. alternata wild type (Fig. 6B).
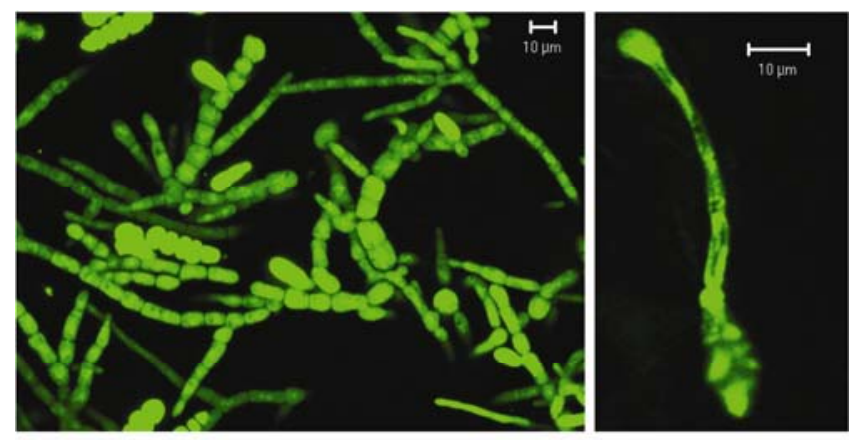

Hyg R

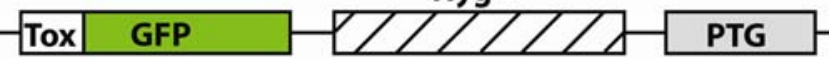

Fig. 5. Green fluorescent protein (GFP)-tagged N-acetylglucosaminidase gene disruption mutants. Left panel shows GFP expression of a mutant growing on hygromycin containing potato dextrose agar while the right panel shows an appressorium-like structure at the hyphal tip of a germinated spore on a Brassica oleracea (green cabbage) leaf surface $12 \mathrm{~h}$ following inoculation. Abbreviations: Tox $=$ ToxA promoter and $\mathrm{PTG}=$ partial target gene.

\section{DISCUSSION}

The combination of partial target gene sequences disrupted by vector sequences as well as the orientation of vector sequences in transformants indicates that targeted gene disruption in our system was accomplished by a single homologous recombination preceded by circularization of the linear construct, and not by nonhomologous DNA end joining (Convery et al. 2005; Critchlow and Jackson 1998; Pastink et al. 2001). We hypothesize that multiple steps of enzymatic activity occur during the incorporation of the disruption construct into the genome. From our data, we inferred that endogenous exonucleases are involved in the gradual digestion of linear constructs from both ends, followed by intramolecular ligation to make circular DNA (Fig. 7). In three (ace1, ace7, and ace8) of nine mutants for $N$-acetylglucosaminidase gene mutants, intermolecular ligation preceded intramolecular ligation, although we do not rule out a possibility of multiple homologous recombination events. However, none of these complications affect the production of targeted $\mathrm{KO}$ mutants to a great degree and should not be considered problematic.

With the LME constructs consisting of minimal components, we were able to produce transformants in every trial with approximately 20 genes. We were able to generate approximately 15 transformants per construct with $10 \mu \mathrm{g}$ of purified PCR products in approximately $4 \times 10^{6}$ protoplast with an optimized protocol in three A. brassicicola isolates tested. Targeted gene disruption efficiency was improved dramatically with the LME constructs compared with standard plasmid disruption constructs. These results may be attributed to the small size of the linear constructs or intrinsic differences between plasmids and linear DNA. The typical minimal linear construct $(2 \mathrm{~kb})$ is approximately threefold smaller than the plasmid $(5.5 \mathrm{~kb})$ used in this study. Alternatively, the linear DNA might enhance both transformation and targeted gene disruption efficiencies as shown in A. alternata (Shiotani and Tsuge 1995) due to uncharacterized reasons. However, substantial differences in transfor-
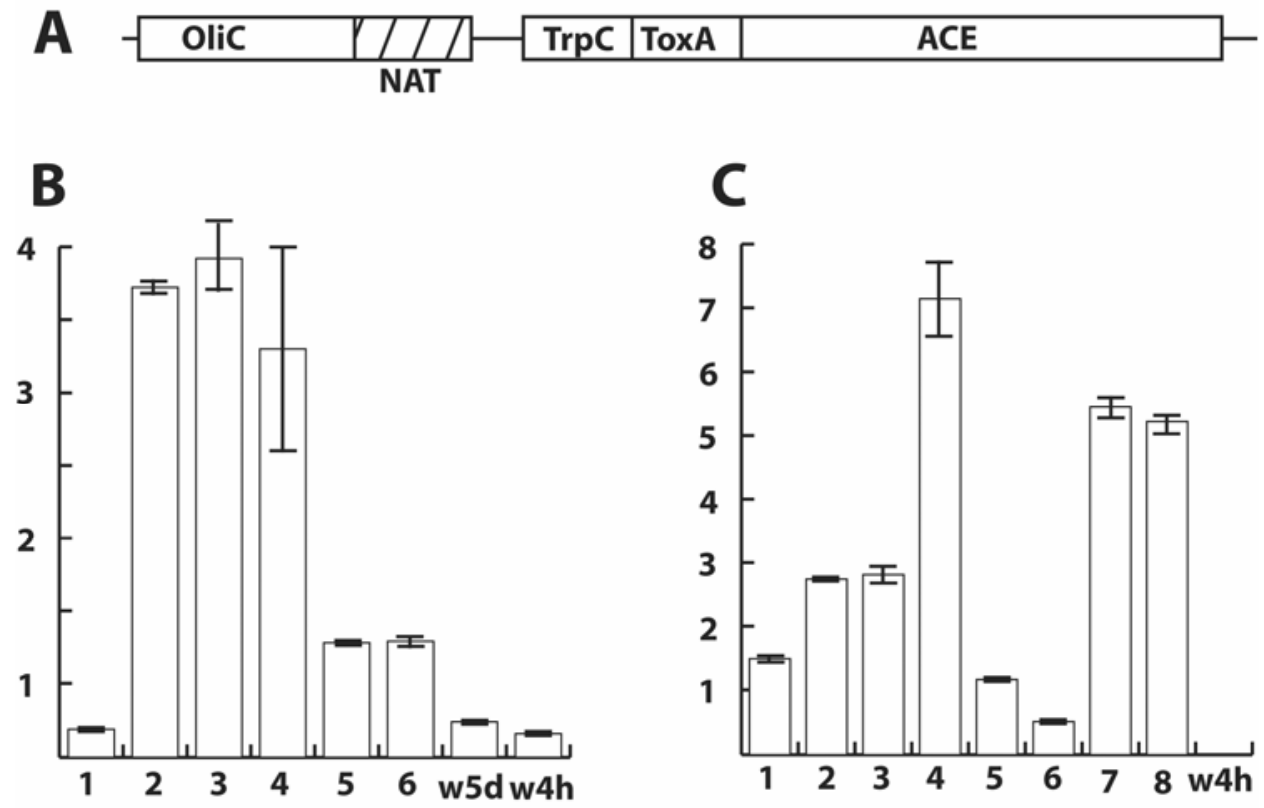

Fig. 6. Overexpression of N-acetylglucosaminidase gene measured by quantitative reverse-transcriptase polymerase chain reaction. A, Shown is a schematic diagram of a linear minimal element (LME) overexpression construct. Antibiotic resistance marker gene cassettes (OliC promoter and nourseothricin acetyltransferase gene) precede the N-acetylglucosaminidase gene with $\operatorname{Trp} C$ and $\operatorname{Tox} A$ promoter sequences. Gene expression level is presented for B, six transformants in Alternaria brassicicola and $\mathbf{C}$, eight transformants in an A. alternata wild-type background. Sample RNA was extracted from mycelia grown in glucose-yeast extract (GYEB) media for $4 \mathrm{~h}$. The X-axes show sample identification and Y-axes show absolute amounts of transcripts (femtogram) in 5 ng of total RNA. The line on each bar graph indicates standard deviation among three technical samples. Abbreviations: w5d = wild-type mycelia grown in GYEB for 5 days and $\mathrm{w} 4 \mathrm{~h}=$ wild-type mycelia grown in GYEB for $4 \mathrm{~h}$. 
mation efficiency were not observed between LME and plasmids disruption constructs. The major difference observed between the two methods was in reliable targeting efficiency.

In most cases, gene disruption efficiency was $100 \%$ in three A. brassicicola isolates with the LME disruption construct. Importantly, the majority of mutants contain a single copy of transforming DNA. Our results show greatly increased efficiency compared with examples of approximately $40 \%$ gene disruption efficiency in other systems with either Agrobacterium-mediated transformation or transposon-mediated library construction (Adachi et al. 2002; Hamer et al. 2001; Mullins et al. 2001; Zwiers and De Waard 2001). Moreover, our results are comparable with the targeted gene disruption efficiency of $N$. crassa in nonhomologous DNA end-joining machinery mutant background (Ninomiya et al. 2004) and Alternaria alternata with linearized disruption constructs (Shiotani and Tsuge 1995). Although both examples showed $100 \%$ gene targeting efficiency, the LME disruption method has merits over them in its simplicity to create the constructs and isolate pure mutants, and in the tendency of a single-copy insertion of the disruption constructs into the genome. In addition, similar constructs are applicable to generate GFP-tagged disruption mutants (Fig. 5) and targeted-gene overexpressing mutants (Fig. 6). The former could be useful, for example, when examining interactions of mutants with host plants in downstream pathogenicity assays, whereas the latter could be useful for complementation of preexisting mutants or identification of subtle virulence factors through a gain of function approach.

This method is applicable for the integration of EST or genome sequence information with the functional analysis of each gene by a reverse genetics approach. Combined with PCR-based construct generation (Yang et al. 2004), it appears possible to use LME constructs for an initial high-throughput screen to study the effect of individual genes on biological functions. It is conceivable to make a synthetic oligo library for every single gene identified in silico (Cho and Walbot 2001), followed by PCR amplification of the target gene with a selectable marker gene.

In this study, we have described a relatively straightforward, extremely efficient method for disrupting genes in A. brassicicola. This approach appears quite suitable for development of a high-throughput functional genomics platform for analyzing gene function in an organism whose genome sequence is soon to be made publicly available. Other than the role of host-specific fungal toxins in pathogenesis, our basic understanding of the subtleties underlying interactions of plants with necrotrophic fungi is still in its infancy. For example, it is becoming apparent that only specific gene family members encoding secreted plant cell wall-degrading enzymes are required for full virulence of necrotrophs such as A. alternata and Botrytis cinerea on specific plants and plant parts (Isshiki et al. 2001; Kars et al. 2005). The high-throughput approach described here will allow for the systematic functional analysis of large sets of candidate genes such as those predicted to encode cell wall-degrading enzymes and other genes of interest identified through bioinformatic analysis of the A. brassicicola genome sequence. In summary, the method reported here undoubtedly will aid in the identification of fungal proteins and secondary metabolites representing major players at the host-pathogen interface in both compatible interactions with cultivated Brassicas and various interactions with Arabidopsis ecotypes and mutants.

\section{MATERIALS AND METHODS}

\section{Fungi.}

A. brassicicola isolates ATCC34622, ATCC96866, and AB7 were used in this study. ATCC96866 is the isolate being se- quenced. A. brassicicola was routinely cultured on PDA media (Difco, Kansas City, MO, U.S.A.). A. alternata isolate ATCC11680 was used in this study.

\section{Generation of disruption constructs.}

Based on the cDNA sequence, two primers with an enzymatic site at each end were designed to amplify a 250- to 500$b p$ fragment within the coding region of each gene. DNA sequences corresponding to genes used in this study are available upon request from C. B. Lawrence. PCR products were digested with the two endonucleases and ligated into the multiple cloning site of pCB1636 plasmid (Sweigard et al. 1995). The plasmid construct was transformed in Escherichia coli DH5 $\alpha$ (Invitrogen, Carlsbad, CA, U.S.A.) to produce over $10 \mu \mathrm{g}$ of plasmid. The plasmid constructs were sequenced to verify the presence of target gene sequences in the vector. These constructs were used in either transformation experiments in their circular form or PCR reactions to generate linear DNA. Constructs were used as template DNA to amplify between M13 forward and M13 reverse priming sites that contained the hygB phosphotransferase gene under control of the $\operatorname{trp} C$ fungal promoter and the cloned partial targeted gene. The PCR products were purified with the PCR Clean Up kit (Qiagen, Palo Alto, CA, U.S.A.) and further concentrated to a concentration of $1 \mu \mathrm{g} / \mu \mathrm{l}$ in a Speedvac (Eppendorf, Barkhausenweg, Germany).

\section{GFP-tagged construct and overexpression constructs.}

To make GFP-tagged LME disruption constructs, we added GFP cassettes in front of hygB resistance cassettes (Fig. 5). The GFP cassettes containing ToxA promoter and a GFP coding gene were amplified with primers $5^{\prime}$-acggggtaccTTGGAATG

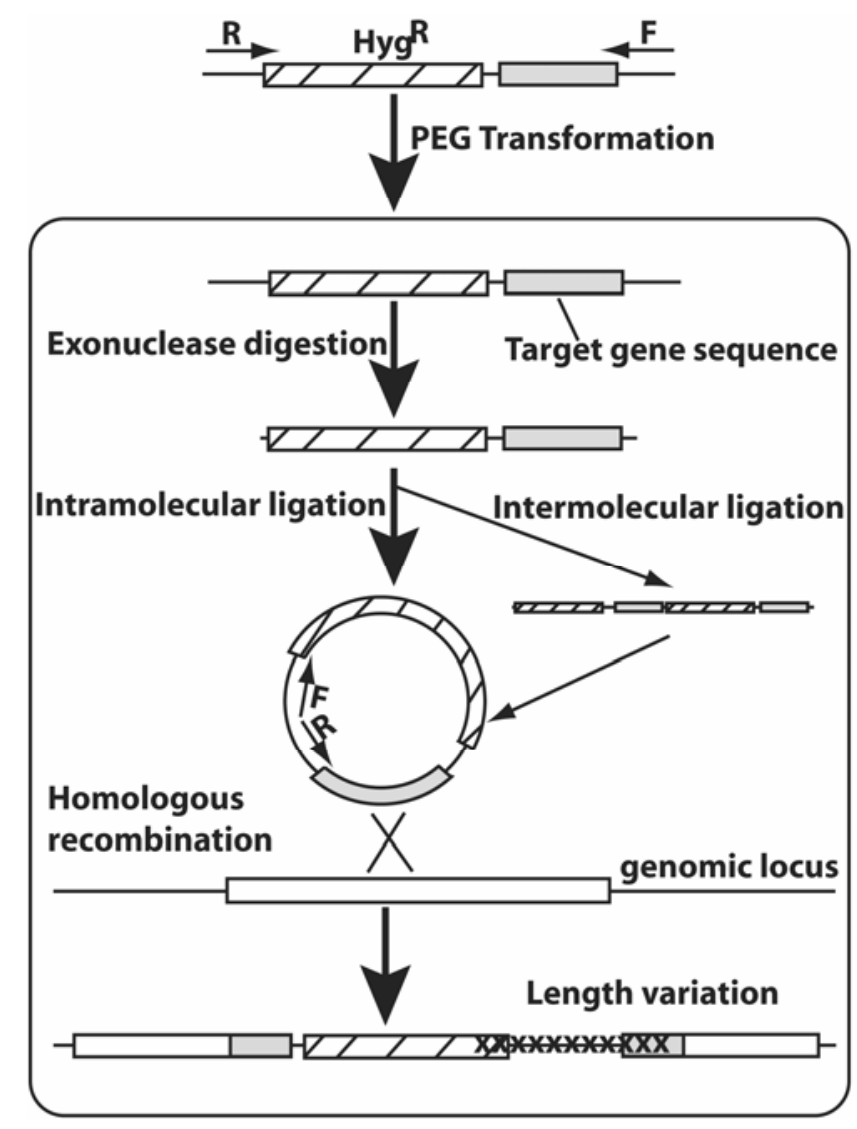

Fig. 7. Model of the molecular mechanism of targeted gene disruption via homologous recombination with a linear minimal element (LME) disruption construct. All enzyme reactions were inferred to occur in the fungal cells (protoplasts) after DNA uptake. 
CATGGAGGAGT-3' and 5'-ttatctcgagTTGCGCGCTATATTT TGTTTT-3' using pCT74 as template DNA (Lorang et al. 2001). The PCR products were digested with XhoI and KpnI and cloned in pCB-Nac to make plasmid pCB16G6-Nac. Cloning and plasmid production were performed as described in the previous section. A fragment containing GFP cassettes, Hyg cassettes, and partial $N$-acetylglucossaminidase (GFP-tagged LME disruption constructs) was amplified using pCB16G6Nac as template DNA with M13 forward and M13 reverse primers. The PCR products were transformed in wild-type $A$. brassicicola to make GFP-tagged $N$-acetylglucosaminidase disruption mutants.

An LME overexpression cassette for $N$-acetylglucosaminidase was made by cloning Nourseothricin-resistant cassettes, two constitutive promoters, and partial target gene in pBluscript II SK(-), at SpeI and PstI sites, HindIII and XbaI sites, and ApaI and XhoI sites, respectively. Nourseothricin cassettes were amplified with primers 5'-GTGCACTAGTTCA TTCTAGCTTGCGGTCCT-3' and 5'-ACATCCACGGGACTT GAGAC-3' using pNR as template DNA (Malonek et al. 2004). ToxA and TrpC promoters were amplified with primers 5'-GGC TCTCGAGTTTGGATGCTTGGGTAGAATAG-3' and 5'-TT $^{\prime}$ GCTAAGCTTGGCCTATATTCATTCATTGTCAGC-3' using pCT74 as template DNA (Lorang et al., 2001). Partial sequence of $N$-acetyl glucosaminidase was amplified with primers 5'-ACAACTCGAGCAGCAATGCGCGATTTCATA-3' and 5'-AGGTGGGCCCTACGCCGTCTGGTTCAAATAC-3') using A. brassicicola genomic DNA from the start codon.

\section{A. brassicicola transformation.}

Transformation was carried out with either plasmid disruption constructs or linear PCR products based on the transformation protocol of A. alternata (Akamatsu et al. 1997), with modifications. Approximately $5 \times 10^{6}$ fungal conidia were harvested from a PDA culture plate and inoculated into $50 \mathrm{ml}$ of GYEB ( $1 \%$ glucose and $0.5 \%$ yeast extract) media. They were cultured for $36 \mathrm{~h}$ with shaking at $100 \mathrm{rpm}$ at $25^{\circ} \mathrm{C}$. The mycelia were harvested by centrifugation at $2,000 \times g$ for $5 \mathrm{~min}$ and washed with $0.7 \mathrm{M} \mathrm{NaCl}$ followed by centrifugation again under the same conditions as before. The mycelia were digested in $6 \mathrm{ml}$ of Kitalase (Wako Chemicals, Richmond, VA, U.S.A.) at $10 \mathrm{mg} / \mathrm{ml}$ in $0.7 \mathrm{M} \mathrm{NaCl}$ for 3 to $4 \mathrm{~h}$ at $28^{\circ} \mathrm{C}$ with constant shaking at 110 $\mathrm{rpm}$. The protoplasts were collected by centrifugation at $700 \times g$ for $10 \mathrm{~min}$ at $4^{\circ} \mathrm{C}$, washed twice with $10 \mathrm{ml}$ of $0.7 \mathrm{M} \mathrm{NaCl}$ and then with $10 \mathrm{ml}$ of STC buffer (1 M Sorbitol, $50 \mathrm{mM}$ Tris-HCL, $\mathrm{pH} 8.0$, and $50 \mathrm{mM} \mathrm{CaCl}_{2}$ ). The protoplasts were resuspended in STC at a concentration of $4 \times 10^{6}$ in $70 \mu \mathrm{l}$, after which $10 \mu \mathrm{g}$ of plasmid or PCR products in $10 \mu \mathrm{l}$ of $\mathrm{ddH}_{2} \mathrm{O}$ was added to the protoplast and gently mixed. The transformation mix was incubated on ice for $30 \mathrm{~min}$. Heat shock transformation was performed by incubating the transformation mixture at $42^{\circ} \mathrm{C}$ for 2 to $10 \mathrm{~min}$. The transformation mix was incubated at room temperature after the addition of $800 \mu \mathrm{l}$ of $40 \%$ PEG solution. Then, $200 \mu \mathrm{l}$ of the transformation mixture was added to $25 \mathrm{ml}$ of molten regeneration medium ( $1 \mathrm{M}$ sucrose, $0.5 \%$ yeast extract, $0.5 \%$ casein amino acids, and $1 \%$ agar,) in a 50-ml tube and subsequently poured into a 100-by-15-mm petri dish. After $24 \mathrm{~h}$, the plates were overlaid with $25 \mathrm{ml}$ of hygB (Sigma-Aldrich, St. Louis, U.S.A.) containing PDA at $30 \mu \mathrm{g} / \mathrm{ml}$. Individual hygBresistant transformants were transferred to a fresh hygB-containing plate between 10 and 15 days after each transformation. Each transformant was purified further by transferring a single spore to a fresh hygB-containing plate.

\section{DNA isolation.}

Total genomic DNA from A. brassicicola was extracted using a phenol-chloroform extraction method. Fungi were grown for
2 to 3 days in $50 \mathrm{ml}$ of GYEB media. Approximately $0.2 \mathrm{~g}$ of mycelia was harvested and filtered with Miracloth (Calbiochem, Darmstadt, Germany), semi-dried with paper towels, and ground into fine powder with a mortar and pestle in the presence of liquid nitrogen. The samples were mixed with $1 \mathrm{ml}$ of extraction buffer $(0.7 \mathrm{M} \mathrm{NaCl}, 1 \%$ cetyltrimethylammonium bromide, $50 \mathrm{mM}$ Tris-HCL, pH8.0, and $10 \mathrm{mM}$ EDTA) and $10 \mu \mathrm{lof}$ RNAse A (Sigma-Aldrich) at $100 \mathrm{mg} / \mathrm{ml}$ and incubated at $60^{\circ} \mathrm{C}$ for $30 \mathrm{~min}$. Water $(1 \mathrm{ml})$ was added to the tube and extracted with $2 \mathrm{ml}$ of Tris-saturated phenol, followed by chloroform extraction. DNA was separated from the solution by adding an equal volume of cold ethanol to the upper phase. DNA was transferred with a plastic stick to a clean tube and washed with $70 \%$ ethanol.

\section{Mutant verification with PCR.}

The genomic DNA was used for PCR verification of the disruption mutants with a gene-specific primer and a hyg $B$ genespecific primer, or two gene-specific primers outside of the disruption construct. A total of $30 \mathrm{ng}$ of genomic DNA was used in each $20-\mu$ l PCR reaction in a GeneAmp PCR system 2700 thermocycler (ABI, Foster City, CA, U.S.A.). With the gene-specific and hygB-specific primers, PCR reactions were performed with $\mathrm{Taq}$ polymerase to amplify approximately 2.5 $\mathrm{kb}$ by $94^{\circ} \mathrm{C}$ denaturation for $5 \mathrm{~min}$ followed by 30 cycles of 30 $\mathrm{s}$ of denaturation at $94^{\circ} \mathrm{C}, 30 \mathrm{~s}$ of annealing at $55^{\circ} \mathrm{C}$, and $2 \mathrm{~min}$ of elongation at $72^{\circ} \mathrm{C}$. After the cycling reactions, the final elongation was performed at $72^{\circ} \mathrm{C}$ for $7 \mathrm{~min}$. With gene-specific primers only, PCR reactions were performed with AccuPrime Taq (Invitrogen) by $94^{\circ} \mathrm{C}$ denaturation for $1.5 \mathrm{~min}$ followed by 30 cycles of $10 \mathrm{~s}$ of denaturation at $94^{\circ} \mathrm{C}, 10 \mathrm{~s}$ of annealing at $55^{\circ} \mathrm{C}$, and $3.3 \mathrm{~min}$ of elongation at $68^{\circ} \mathrm{C}$. PCR products were size fractionated on $1 \%$ agarose gel by electrophoresis and visualized by ethidium bromide staining.

\section{Southern hybridization analysis.}

A total of 2 to $3 \mu \mathrm{g}$ of genomic DNA was digested with selected enzymes purchased from New England BioLab (Beverly, MA, U.S.A.). The digested DNA was size fractionated on a $0.7 \%$ agarose gel, followed by transfer to Hybond $\mathrm{N}+$ nylon membrane (Amersham, Piscataway, NJ, U.S.A.). DNA probes were synthesized using a PCR digoxigenin (DIG) Probe Synthesis Kit according to the manufacturer's manual (Roche Diagnostics, Mannheim, Germany). Hybridization of membranes was performed at $50^{\circ} \mathrm{C}$ using the Block and Wash Buffer set according to the manufacturer's instructions (Roche Diagnostics). Membranes were washed in a final solution of $0.1 \times \mathrm{SSC}(1 \times \mathrm{SSC}$ is $0.15 \mathrm{M} \mathrm{NaCl}$ plus $0.015 \mathrm{M}$ sodium citrate) and $0.1 \%$ sodium dodecyl sulfate at $68^{\circ} \mathrm{C}$. Chemiluminescent detection was used to develop the blots with CDP-Star using the DIG detection kit according to the manufacturer's instructtions (Roche Diagnostics).

\section{Quantitative real-time PCR.}

RNA was extracted from $0.1 \mathrm{~g}$ of mycelia grown in GYEB media using the Plant RNeasy kit (Qiagen). RNA samples were checked for quality on the Agilent Bioanalyzer 2100 (Agilent, Palo Alto, CA, U.S.A.). Then, $1 \mu \mathrm{g}$ of total RNA was transcribed to cDNA in $20 \mu \mathrm{l}$ using the Biorad I-script kit. Each cDNA was diluted 1:10, with $1 \mu \mathrm{l}$ (5 ng of total RNA) used per reaction. Reactions consisted of $300 \mathrm{nM}$ sense and antisense primers, $1 \mu \mathrm{l}$ of diluted cDNA, and reverse transcriptase-grade PCR water to a final volume of $12.5 \mu \mathrm{l}$. SyBr-Green Supermix (Biorad, Hercules, CA, U.S.A.) was added to obtain a final running volume of $25 \mu \mathrm{l}$ per reaction. Each reaction was run in triplicate for both the standard and unknown samples. Reactions were run under the following conditions in the Bio- 
rad I-cycler (Biorad): $95^{\circ} \mathrm{C}$ denaturation for $3 \mathrm{~min}, 40$ cycles of $95^{\circ} \mathrm{C}$ for $10 \mathrm{~s}, 56^{\circ} \mathrm{C}$ for $15 \mathrm{~s}$, and $72^{\circ} \mathrm{C}$ for $20 \mathrm{~s}$ to calculate cycle threshold values, followed by $95^{\circ} \mathrm{C}$ for $1 \mathrm{~min}, 55^{\circ} \mathrm{C}$ for 1 min, and 80 times of $55^{\circ} \mathrm{C}$ for $10 \mathrm{~s}$, increasing temperature by $0.5^{\circ} \mathrm{C}$ each cycle to obtain melt curves and, subsequently, to enable data analyses. Standard curves were produced with purified amplified DNA products of 10 and $1 \mathrm{pg} / \mu \mathrm{l}$ and starting concentrations of 100,10 , and $1 \mathrm{fg} / \mu \mathrm{l}$. A baseline subtracted curve fit was used to generate standard curve data. Absolute amounts of transcripts were calculated using a correlation coefficient formula generated from the standard curve in each run without length correction of 1.8-kb actual transcripts compared with 200-bp amplicons.

\section{ACKNOWLEDGMENTS}

This material is based upon work supported by the National Science Foundation under grant number 0443991 to C. B. Lawrence. We would like to thank T. K. Mitchell (Center for Integrated Fungal Research, Raleigh, NC, U.S.A.) for helpful discussions, J. Lorang and L. Ciuffetti (Oregon State University) and J. Van Kan (Wageningen Agricultural University) for providing pCT74 and pNR vectors, H. Van Etten and B. Pryor (Arizona State University) for helpful discussions regarding fungal transformation and providing the saprophytic A. alternata isolate, and S. Conrad at VBI core laboratory facility for the quantitative real-time PCR performance.

\section{LITERATURE CITED}

Adachi, K., Nelson, G. H., Peoples, K. A., Frank, S. A., MontenegroChamorro, M. V., DeZwaan, T. M., Ramamurthy, L., Shuster, J. R., Hamer, L., and Tanzer, M. M. 2002. Efficient gene identification and targeted gene disruption in the wheat blotch fungus Mycosphaerella graminicola using TAGKO. Curr. Genet. 42:123-127.

Akamatsu, H., Itoh, Y., Kodama, M., Otani, H., and Kohmoto, K. 1997. AAL-toxin-deficient mutants of Alternaria alternata tomato pathotype by restriction enzyme mediated integration. Phytopathology 87:967-972.

Bussink, H. J., and Osmani, S. A. 1999. A mitogen-activated protein kinase (MPKA) is involved in polarized growth in the filamentous fungus, Aspergillus nidulans. FEMS (Fed. Eur. Microbiol. Soc.) Microbiol. Lett. 173:117-125.

Cho, Y., and Walbot, V. 2001. Computational methods for gene annotation: the Arabidopsis genome. Curr. Opin. Biotechnol. 12:126-130.

Convery, E., Shin, E. K., Ding, Q., Wang, W., Douglas, P., Davis, L. S., Nickoloff, J. A., Lees-Miller, S. P., and Meek, K. 2005. Inhibition of homologous recombination by variants of the catalytic subunit of the DNA-dependent protein kinase (DNA-PKcs). Proc. Natl. Acad. Sci. U.S.A. 102:1345-1350.

Critchlow, S. E., and Jackson, S. P. 1998. DNA end-joining: from yeast to man. Trends Biochem. Sci. 23:394-398.

Galagan, J. E., Calvo, S. E., Borkovich, K. A., Selker, E. U., Read, N. D., Jaffe, D., FitzHugh, W., Ma, L. J., Smirnov, S., Purcell, S., Rehman, B., Elkins, T., Engels, R., Wang, S., Nielsen, C. B., Butler, J., Endrizzi, M., Qui, D., Ianakiev, P., Bell-Pedersen, D., Nelson, M. A., WernerWashburne, M., Selitrennikoff, C. P., Kinsey, J. A., Braun, E. L., Zelter, A., Schulte, U., Kothe, G. O., Jedd, G., Mewes, W., Staben, C., Marcotte, E., Greenberg, D., Roy, A., Foley, K., Naylor, J., Stange-Thomann, N., Barrett, R., Gnerre, S., Kamal, M., Kamvysselis, M., Mauceli, E., Bielke, C., Rudd, S., Frishman, D., Krystofova, S., Rasmussen, C., Metzenberg, R.L., Perkins, D. D., Kroken, S., Cogoni, C., Macino, G., Catcheside, D., Li, W., Pratt, R. J., Osmani, S. A., DeSouza, C. P., Glass, L., Orbach, M. J., Berglund, J. A., Voelker, R., Yarden, O., Plamann, M., Seiler, S., Dunlap, J., Radford, A., Aramayo, R., Natvig, D. O., Alex, L. A., Mannhaupt, G., Ebbole, D. J., Freitag, M., Paulsen, I., Sachs, M. S., Lander, E. S., Nusbaum, C., and Birren, B. 2003. The genome sequence of the filamentous fungus Neurospora crassa. Nature 422:859-868.

Hamer, L., Adachi, K., Montenegro-Chamorro, M. V., Tanzer, M. M., Mahanty, S. K., Lo, C., Tarpey, R. W., Skalchunes, A. R., Heiniger, R. W., Frank, S. A., Darveaux, B. A., Lampe, D. J., Slater, T. M., Ramamurthy, L., DeZwaan, T. M., Nelson, G. H., Shuster, J. R., Woessner, J., and Hamer, J. E. 2001. Gene discovery and gene function assignment in filamentous fungi. Proc. Natl. Acad. Sci. U.S.A. 98:5110-5115.

Hynes, M. J. 2003. The Neurospora crassa genome opens up the world of filamentous fungi. Genome Biol. 4:217.

Isshiki, A., Akimitsu, K., Yamamoto, M., and Yamamoto, H. 2001. Endopolygalacturonase is essential for citrus black rot caused by Alternaria citri but not brown spot caused by Alternaria alternata. Mol. PlantMicrobe Interact. 14:749-757.

Jones, T., Feerspiel, N. A., Chibana, H., Dungan, J., Kalman, S., Magee, B. B., Newport, G., Thorstenson, Y. R., Agabian, N., Magee, P. T., Davis, R. W., and Scherer, S. 2004. The diploid genome sequence of Candida albicans. Proc. Natl. Acad. Sci. U.S.A. 101:7329-7334.

Kars, I., Krooshof, G. H., Wagemakers, L., Joosten, R., Benen, J. A. E., and van Kan, J. A. L. 2005. Necrotizing activity of five Botrytis cinerea endopolygalacturonases produced in Pichia pastoris. Plant J.43: 213225.

Lo, C., Adachi, K., Shuster, J. R., Hamer, J. E., and Hamer, L. 2003. The bacterial transposon $T n 7$ causes premature polyadenylation of mRNA in eukaryotic organisms: TAGKO mutagenesis in filamentous fungi. Nucleic Acids Res. 31:4822-4827.

Lorang, J. M., Tuori, R. P., Martinez, J. P., Sawyer, T. L., Redman, R. S., Rollins, J. A., Wolpert, T. J., Johnson, K. B., Rodriguez, R. J., Dickman, M. B., and Ciuffetti, L. M. 2001. Green fluorescent protein is lighting up fungal biology. Appl. Environ. Microbiol. 67:1987-1994.

Malonek, S., Rojas, M. C., Hedden, P., Gaskin, P., Hopkins, P., and Tudzynski, B. 2004. The NADPH-cytochrome P450 reductase gene from Gibberella fujikuroi is essential for gibberellin biosynthesis. J. Biol. Chem. 279:25075-25084.

Martin-Hernandez, A. M., Dufresne, M., Hugouvieux, V., Melton, R., and Osbourn, A. 2000. Effects of targeted replacement of the tomatinase gene on the interaction of Septoria lycopersici with tomato plants. Mol. Plant-Microbe Interact. 13:1301-1311.

Mullins, E., Chen, X., Romaine, P., Raina, R., Geiser, D., and Kang, S. 2001. Agrobacterium-mediated transformation of Fusarium oxysporum: an efficient tool for insertional mutagenesis and gene transfer. Phytopathology 91:173-180.

Ninomiya, Y., Suzuki, K., Ishii, C., and Inoue, H. 2004. Highly efficient gene replacements in Neurospora strains deficient for nonhomologous end-joining. Proc. Natl. Acad. Sci. U.S.A. 101:12248-12253.

Pastink, A., Eeken, J. C., and Lohman, P. H. 2001. Genomic integrity and the repair of double-strand DNA breaks. Mutat. Res. 480-481:37-50.

Punt, P. J., Oliver, R. P., Dingemanse, M. A., Pouwels, P. H., and Van den Hondel, C. A. 1987. Transformation of Aspergillus based on the hygromycin B resistance marker from Escherichia coli. Gene 56:117-124.

Schmitt, E. K., Hoff, B., and Kuck, U. 2004. AcFKH1, a novel member of the forkhead family, associates with the RFX transcription factor CPCR1 in the cephalosporin C-producing fungus Acremonium chrysogenum. Gene 342:269-281.

Shah-Mahoney, N., Hampton, T., Vidaver, R., and Ratner, D. 1997. Blocking the ends of transforming DNA enhances gene targeting in Dictyostelium. Gene 203:33-41.

Shiotani, H., and Tsuge, T. 1995. Efficient gene targeting in the filamentous fungus Alternaria alternata. Mol. Gen. Genet. 248:142-150.

Sweigard, J. A., and Ebbole, D. J. 2001. Functional analysis of pathogenicity genes in a genomics world. Curr. Opin. Microbiol. 4:387-392.

Sweigard, J. A., Carroll, A. M., Kang, S., Farrall, L., Chumley, F. G., and Valent, B. 1995. Identification, cloning, and characterization of PWL2, a gene for host species specificity in the rice blast fungus. Plant Cell 7:1221-1233.

Sweigard, J. A., Carroll, A. M., Farrall, L., Chumley, F. G., and Valent, B. 1997. A series of vectors for fungal transformation. Fungal Genet. Newsl. 44:52-53.

Tsuge, T., Nishimura, S., and Kobayashi, H. 1990. Efficient integrative transformation of the phytopathogenic fungus Alternaria alternata mediated by the repetitive rDNA sequences. Gene 90:207-214.

Voigt, C. A., Schafer, W., and Salomon, S. 2005. A secreted lipase of Fusarium graminearum is a virulence factor required for infection of cereals. Plant J. 42:364-375.

Yang, L., Ukil, L., Osmani, A., Nahm, F., Davies, J., De Souza, C. P., Dou, X., Perez-Balaguer, A., and Osmani, S. A. 2004. Rapid production of gene replacement constructs and generation of a green fluorescent protein-tagged centromeric marker in Aspergillus nidulans. Eukaryot. Cell 3:1359-1362.

Yao, C., and Köller, W. 1995. Diversity of cutinases from plant pathogenic fungi: different cutinases are expressed during saprophytic and pathogenic stages of Alternaria brassicicola. Mol. Plant-Microbe Interact. 8:122-130.

Zwiers, L. H., and De Waard, M. A. 2001. Efficient Agrobacterium tumefaciens-mediated gene disruption in the phytopathogen Mycosphaerella graminicola. Curr. Genet. 39:388-393.

\section{AUTHOR-RECOMMENDED INTERNET RESOURCE}

Broad Institute's Fungal Genome Initiative webpage: www.broad.mit.edu/annotation/fgi/ 